\title{
Post mortem identification of Kalicephalus colubri colubri (Nematoda: Diaphanocephalidae) in a captive Mole snake (Pseudaspis cana) in South Africa
}

\author{
$\mathrm{K}$ Junker $^{\mathrm{a}}$, E P Lane ${ }^{\mathrm{b}}$, B Dlamini ${ }^{\mathrm{b}}, \mathrm{A} \mathrm{Kotze}^{\mathrm{b}, \mathrm{c}}$ and J Boomker ${ }^{\mathrm{a}^{*}}$
}

\begin{abstract}
Necropsy examination of a captive emaciated, dehydrated adult female Mole snake (Pseudaspis cana) in October 2007 revealed multiple cutaneous abscesses. Other findings included renal and hepatic atrophy, hepatic haemosiderosis, multifocal granulomatous hepatitis associated with acid-fast bacteria as well as pulmonary congestion and oedema. Large numbers of the nematode Kalicephalus colubri colubri were recovered from the oesophagus and stomach, representing the 1st reported case of K. colubri from a Mole snake in South Africa. The lesions caused by K. c. colubri were insignificant, but the presence of worms may have contributed to weight loss.
\end{abstract}

Key words: cachexia, Kalicephalus colubri colubri, Nematoda, Pseudaspis cana, skin ulceration. Junker K, Lane E P, Dlamini B, Kotze A, Boomker J Post-mortem identification of Kalicephalus colubri colubri (Nematoda: Diaphanocephalidae) in a captive Mole snake (Pseudaspis cana) in South Africa. Journal of the South African Veterinary Association (2009) 80(1): 54-56 (En.). Department of Veterinary Tropical Diseases, University of Pretoria, Private Bag X04, Onderstepoort, 0110 South Africa.

\section{INTRODUCTION}

The Mole snake (Pseudaspis cana) is a constrictor with a wide distribution throughout southern Africa. Its range extends northwards to Angola and eastwards to Kenya. In South Africa it inhabits a variety of habitats including sandy scrubland in the southwestern Cape, Highveld grassland as well as mountainous and desert regions. Living underground in abandoned burrows, its diet mainly consists of moles, rodents and other small mammals, and therefore it is extremely useful in the control of problem rodents. Although they are quite ferocious when captured and can inflict severe bites, Mole snakes soon settle down in captivity and are said to make good pets ${ }^{2}$.

This clinical communication illustrates some of the potential risks associated with maladaptation to captivity in recently captured free-ranging snakes and intends to draw the attention of exotic wildlife practitioners to the occurrence of Kali-

a'Department of Veterinary Tropical Diseases, University of Pretoria, Private Bag X04, Onderstepoort, 0110 South Africa.

${ }^{b}$ National Zoological Gardens of South Africa, Pretoria, PO Box 754, Pretoria, 0001 South Africa.

Genetics Department, University of the Free State, PO Box 339, Bloemfontein, 9300 South Africa

${ }^{*}$ Author for correspondence.

E-mail: joop.boomker@up.ac.za

Received: June 2008. Accepted: February 2009. cephalus spp. in captive and free-ranging snakes in South Africa. Kalicephalus spp. infection in snakes may be difficult to diagnose as clinical signs such as lethargy and anorexia are non-specific. As with other nematode infections, ante mortem diagnosis depends on identification of adult parasites in regurgitated food or faeces, by stomach endoscopy, or identification of nematode eggs in stomach washings or faecal flotations ${ }^{9}$. Microscopic examination of oesophageal swabs for eggs appears to give better results than cloacal swabs ${ }^{3}$.

\section{CASE HISTORY}

In October 2007 a single adult female Mole snake (186 cm long and weighing $1.39 \mathrm{~kg}$ ), which had been confiscated by the Gauteng Department of Agriculture, Conservation and Environment 2 months previously, died while still in quarantine at the Reptile Park at the National Zoological Gardens, Pretoria. A necropsy was performed the same day.

Necropsy revealed advanced autolysis, dehydration and severe fat and skeletal muscle atrophy (cachexia). The snake had multiple skin ulcerations and foci of depigmentation, $<4 \mathrm{~mm}$ in diameter, mainly on the ventrum. Histologically these ulcers were associated with large chronic subcutaneous abscesses consisting of fibrin and necrotic cellular debris containing colonies of tiny coccobacilli, surrounded by layers of macrophages and epithelioid cells. Bacterial culture of these abscesses yielded a very mixed growth of bacteria, including a heavy growth of Pseudomonas aeruginosa. Additional findings included atrophic kidneys with prominent urates and urate tophi, a distended gall bladder, marked hepatic atrophy, haemosiderosis and mild multifocal granulomatous hepatitis with intralesional acid-fast bacteria, as well as moderately acute diffuse pulmonary congestion and oedema.

Large numbers of filamentous red helminths with a white head $(<1.5 \mathrm{~cm}$ long) occurred in the empty oesophagus and stomach, many attached to the mucosa (Fig. 1), resulting in a moderately diffuse heterophilic infiltration of the submucosa. While not all gastric nematodes were removed, a total of 73 specimens, 57 females and 16 males, were collected and identified as Kalicephalus colubri colubri.

\section{DISCUSSION}

The cause of the Mole snake's death was considered to be a combination of metabolic changes due to marked weight loss and dehydration, as well as pulmonary oedema. Pulmonary oedema could have been caused by heart failure or hypoproteinaemia due to severe weight loss and protein loss in the superficial cutaneous abscesses, as the tissues contained no evidence of widespread systemic vascular damage associated with infectious disease (septic shock) ${ }^{10}$. Marked weight loss, the distended gall bladder and organ atrophy were indicative of long-term anorexia combined with high metabolic need due to chronic infection. Possible causes of anorexia in this snake include metabolic disease, parasitism, failure to adapt to captivity and incorrect ambient temperature. Anorexia and resultant cachexia and dehydration may result from inappropriate environmental temperature and humidity as well as improper feeding practices. Conversely, prolonged inactivity, inappropriate or unhygienic substrate and/or inappropriate environ- 


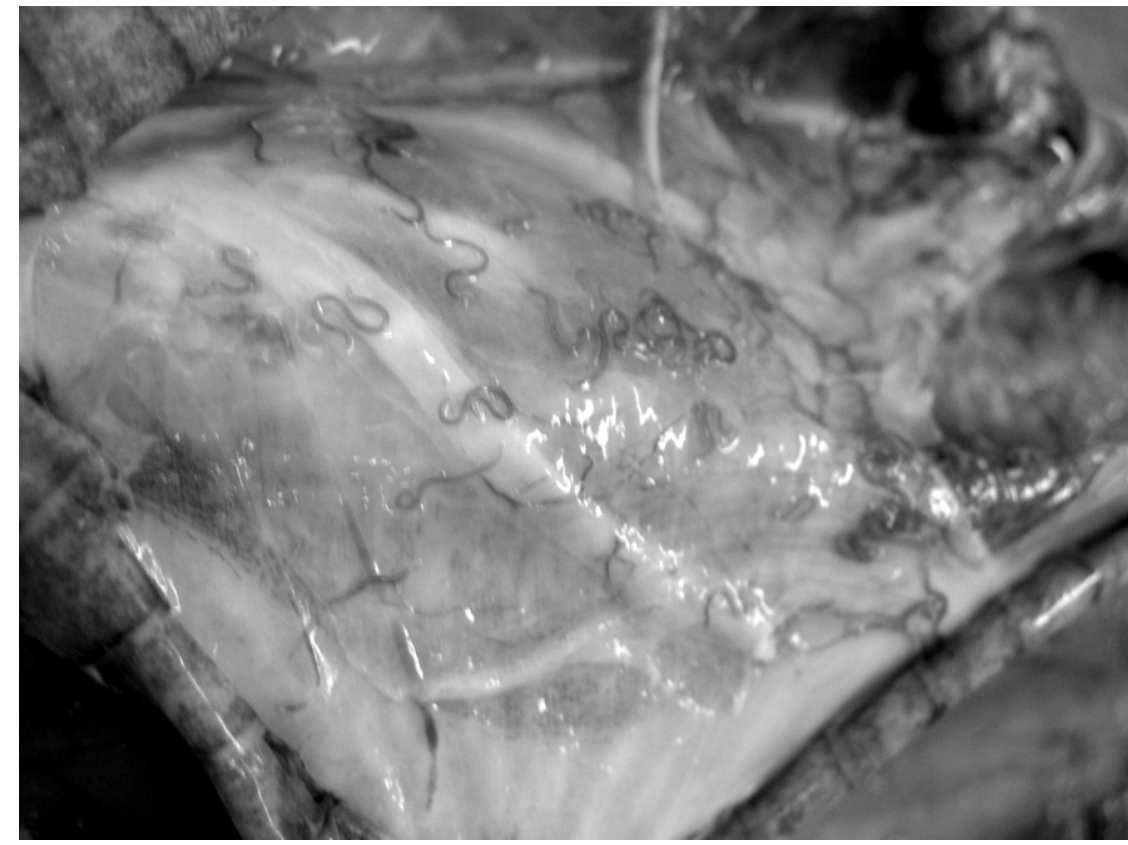

Fig. 1: Kalicephalus colubri colubri attached to the gastric mucosa of Pseudaspis cana.

mental temperature ranges may have played a role in the development of the cutaneous ulcers and abscesses ${ }^{5,11}$. Pseudomonas may have been a primary or secondary pathogen. It has been reported as one of the most common Gram-negative bacterial organisms associated with lesions in snakes ${ }^{11}$ and commonly colonises burn wounds such as those caused by lying on heated pads. ${ }^{8}$. Unfortunately, the hepatic granulomas were microscopic and not seen at necropsy so liver tissue was not submitted for further diagnostic evaluation of the acid-fast bacterial infection. Infections, usually with non-tuberculous mycobacteria, are seen sporadically in well managed reptile collections. Clinical disease, when it occurs, is generally chronic and progressive ${ }^{9}$. In this case, the infection was mild, confined to the liver, and probably of no clinical significance. Mycobacaterial infection in the snake represents no zoonotic risk to human handlers or keepers, but mycobacteria are ubiquitous in soil, and humans, particularly immune-suppressed individuals, may become infected from the same source as the reptile.

The infection with K. c. colubri did not cause significant inflammation in the oesophagus and stomach, but may have affected appetite and subsequently weight loss. Kalicephalus is one of the most common nematode genera parasitising snakes worldwide ${ }^{3,4,6}$. In South Africa, K.c. colubri has been reported from 6 different snake species, the Puff adder (Bitis arietans), the Red-lipped herald (Crotaphopeltis hotamboeia), the Brown house snake (Lamprophis fuliginosus), the Snouted cobra (Naja annulifera), the Mozambique spitting cobra (Naja mossam- bica) and the Short-snouted grass snake (Psammophis brevirostris brevirostris) ${ }^{7}$. Kalicephalus c. colubri has also been found in P. cana in Kenya ${ }^{14}$, in Puff adders in the Congo and in Zambia ${ }^{12,14}$ as well as in the Forest cobra (N. melanoleuca) in West Africa $^{14}$. This is the 1 st report of K. c. colubri from a Mole snake in South Africa. Despite the fact that not all the specimens present were collected, the intensity of $K$. c. colubri in P. cana was distinctly higher than that seen in free-ranging snakes in South Africa, where the highest intensity (40) was recorded from a Puff adder and the mean intensity of infection in the above-mentioned South African snakes ranged from 1 to 10 (ref. 6).

Reports on the pathology caused by Kalicephalus spp. are conflicting and the parasites' effect on the snakes seems to be strongly influenced by whether the hosts are free-ranging or held in captivity ${ }^{4,9}$. Kalicephalus inermis caused acute enteritis with mild lesions in recently caught free-ranging Pit vipers (Bothrops jacaraca) in South America, but caseous enteritis associated with severe lesions in captive specimens that died at a serpentarium ${ }^{4}$. However, these vipers also had several other metazoan and protozoan parasites in the respiratory and gastrointestinal tract which probably contributed to their deaths. Stress associated with captivity may account for the fact that low parasite burdens were severely debilitating to captive snakes while only mild lesions were seen in heavily parasitised freeranging snakes ${ }^{4}$.

Kalicephalus spp. were found at necropsy in 9 different snake species that died at the Nairobi Snake Park ${ }^{3}$. While several of the snakes died of bacterial infections, especially Aeromonas and Pseudomonas, in at least 1 of the snakes, Kalicephalus was judged to be the causative organism. Clinical signs associated with Kalicephalus infection were lethargy and anorexia, especially in cases where the oesophageal lesions were severe ${ }^{3}$. On the other hand, some of the snakes infected with Kalicephalus showed no hyperaemia or inflammation, similar to the current case where few histological changes were associated with the parasite.

Therefore, endoparasites might in themselves not necessarily be highly pathogenic, but the lesions caused by them can easily give rise to secondary bacterial infections ${ }^{13}$. Their demand on the host's resources could make the latter more susceptible to serious pathogens, as the outcome of an individual's reaction to an infectious agent is influenced amongst other factors by its energy resources ${ }^{1}$. Similarly, helminths are opportunistic parasites and a weakened immune system on the part of the host often results in increased intensities of infection. The comparatively high intensity of Kalicephalus seen in the Mole snake is attributed to the debilitating effect of the multiple cutaneous abscesses and the snake's poor body condition.

In conclusion, the case presented here highlights the need for parasitological screening of newly captive snakes, as well as those placed in quarantine. While faecal examination is the most commonly used procedure for the non-invasive detection of helminth infection, the proposed higher efficiency of oesophageal swabs when compared with the former ${ }^{3}$ would warrant investigation as an additional diagnostic tool.

\section{ACKNOWLEDGEMENTS}

This communication arises from necropsy samples collected as part of a research project (07/17) at the National Zoological Gardens: 'Helminth parasites found during post mortem examinations at the National Zoological Gardens of South Africa'. The first author is supported by a University of Pretoria Post-doctoral Fellowship grant.

\section{REFERENCES}

1. Bush A O, Fernandéz J C, Esch G W, Seed J R 2001 Parasitism: The diversity and ecology of animal parasites (1st edn). University Press, Cambridge: 20-21

2. Branch B 1998 Field guide to snakes and other reptiles of southern Africa (3rd edn). Struik, Cape Town

3. Cooper J E 1971 Disease in East African snakes associated with Kalicephalus worms (Nematoda: Diaphanocephalidae). Veterinary Record 89: 385-388

4. Fernandes Grego K, Gardiner C H, CatoDias, J L 2004 Comparative pathology of 
parasitic infections in free-ranging and captive pit vipers (Bothrops jararaca). Veterinary Record 154: 559-562

5. Frye F L 1986 Reptiles. In Fowler M E, Miller $\mathrm{R}$ E (eds) Zoo and wild animal medicine (2nd edn). W B Saunders Company, Philadelphia: 143

6. Hering-Hagenbeck S F B N 2001 The metazoan parasite fauna of South African reptiles, with special attention to their nematodes. PhD thesis, Humboldt-University of Berlin

7. Hering-Hagenbeck S F B N, Boomker J 2000 A check list of the nematode parasites of South African Serpentes (snakes) and
Sauria (lizards). Onderstepoort Journal of Veterinary Research 67: 1-13

8. Jacobsen E R 1981 Diseases of Reptiles. Part II. Infectious Diseases. Compendium on Continuing Education for the Practicing Veterinarian 3: 195-200

9. Jacobsen E R 2007 Parasites and parasitic diseases of reptiles. In Infectious diseases and pathology of reptiles: color atlas and text. Taylor and Francis Group, LLC: 584-592

10. Kobzik L 1999 The lung. In Cotran R S, Kumar V, Collins T (eds) Robbins pathological basis of disease (6th edn). W B Saunders Company, Philadelphia: 700

11. Mitchell M 2003 Ophidia (Snakes). In
Fowler M E, Miller R E (eds) Zoo $\mathcal{E}$ wild animal medicine (5th edn). W B Saunders Company, London: 82-91

12. Peirce M A 1984 Some parasites of reptiles from Zambia and Indian Ocean islands with a description of Haemogregarina zambiensis sp. n. from Dispholydus typus (Colubridae). Journal of Natural History 18: 211-217

13. Riley J 1986 The biology of pentastomids. Advances in Parasitology 25: 45-128

14. Schad G A 1962 Studies on the genus Kalicephalus (Nematoda: Diaphanocephalidae). II. A taxonomic revision of the genus Kalicephalus Molin, 1860. Canadian Journal of Zoology 40: 1035-1167 